\title{
A Case of Graves' Disease Associated with Autoimmune Hepatitis and Mixed Connective Tissue Disease
}

\author{
KaORU INOUE, TAIICHIRo OKAJIMA, EISUKe TANAKA*, BunEI ANDO*, \\ MORISHIGE TAKESHITA**, AKINORI MASUDA***, MASAHIRO YAMAMOTO\#, AND \\ KOUKO SAKAI ${ }^{\#}$ \\ Metabolism and Endocrinology Unit, *Hepato-gastroenterology Unit, **Pathology Unit, \\ ***Otorhinolaryngology Unit, "Rheumatology and Hematology Unit, Clinical Research Institute, \\ National Kyushu Medical Center Hospital, Fukuoka 810-8563, Japan
}

\begin{abstract}
The patient was a woman of forty-eight. Liver dysfunction was pointed out at the age of forty-five. She was admitted to hospital because of her hyperthyroidism. Her palmar skin was wet and her fingers were swollen like sausages. She had a diffuse and elastic hard goiter with a rough surface. The serum levels of free $\mathrm{T}_{3}(9.6 \mathrm{pg} / \mathrm{mL})$ and free $\mathrm{T}_{4}(3.76 \mathrm{ng} / \mathrm{dL})$ were high and that of TSH $(0.11 \mu \mathrm{U} /$ $\mathrm{mL}$ ) was low. The activity of TSH-binding inhibitory immunoglobulin (TBII) was $89 \%$. The uptake rate of 123 I to the thyroid was $55.1 \%$ and the uptake pattern was nearly diffuse. The goiter was proved to contain several nodules by ultrasonography, but aspiration cytology showed no malignant cells. She was diagnosed to have Graves' disease with adenomatous goiter. She also had high ALT (34 IU/L) and $\gamma$ globulin $(1.97 \mathrm{~g} / \mathrm{dL})$. She had positive antinuclear antibody (speckled type), positive anti-ribosomal nuclear protein antibody, and positive LE cell phenomenon. The liver biopsy revealed mononuclear cell infiltration with fibrosis in the portal area. These data indicated that she also had autoimmune hepatitis (AIH) and mixed connective tissue disease (MCTD). The analysis of human leukocyte antigen (HLA) showed positive A11 which had been reported to relate to Graves' disease, and positive DR4 which had been reported to relate to AIH and MCTD. These results suggested that HLA would determine susceptibility to three distinct autoimmune diseases in this case.
\end{abstract}

Key words: Graves' disease, Autoimmune hepatitis, Mixed connective tissue disease, Human leukocyte antigen

(Endocrine Journal 46: 173-177, 1999)

KNOWLEDGE of the pathophysiology of Graves' disease has been greatly increased since identification of TSH receptor antibody and cloning of the cDNA of TSH receptor [1]. Graves' disease is considered to develop mainly due to immunological disorders toward TSH receptor, and

\footnotetext{
Received: April 3, 1998

Accepted: October 2, 1998

Correspondence to: Dr. Kaoru INOUE, Metabolism and Endocrinology Unit, Clinical Research Institute, National Kyushu Medical Center Hospital, 1-8-1 Jigyohama, Chuoku, Fukuoka 810-8563, Japan
}

may be added to the group of autoimmune diseases. Mechanisms in the occurrence of immunological disorders observed in autoimmune diseases have not been fully elucidated. Both genetic and environmental factors are thought to take part in developing immunological disorders. Human leukocyte antigen (HLA) has been considered to be one of the genetic factors which may cause immunological disorders and determine susceptibility to autoimmune diseases. We present a very rare case of Graves' disease associated with autoimmune hepatitis (AIH) and mixed connective tissue disease (MCTD). Etiological evaluation is made through HLA analysis of the case. 


\section{Case Presentation}

The patient was a woman who was found to have liver dysfunction at age of forty-five. At age of forty-seven, she was found to have a goiter. At age of forty-eight, she visited an otorhinolaryngologist in Kyushu Medical Center Hospital for discomfort in the anterior neck in April, 1995. She was then found to have hyperthyroidism and was admitted to the hospital on May 1, 1995. She was $150 \mathrm{~cm}$ in height and weighed $50 \mathrm{~kg}$. Her blood pressure was $110 / 70 \mathrm{mmHg}$, and her pulse rate was $80 / \mathrm{min}$ with a regular rhythm. Her body temperature was $36.7^{\circ} \mathrm{C}$. Her palmar skin was slightly wet but she did not have finger tremor. Her fingers were slightly swollen like sausages and she had noticed Raynaud's phenomenon in winter several times since the end of 1994 . She had mild exophthalmus. Her struma was diffuse and elastic hard, and its surface was irregular. She had systemic lymphadenopathy. Her liver and spleen were not palpable.

Laboratory data on admission are summarized in Table 1. The urinalysis, the analysis of peripheral blood cells, and the hemocoagulation studies were normal, but the serum levels of TTT, ZTT and $\gamma$ globulin were moderately increased. Although the serum levels of ALT, $\gamma$ GTP and ALP were high, that of CPK was normal. Serum levels of free $T_{3}$ $\left(\mathrm{fT}_{3}\right)$ and free $\mathrm{T}_{4}\left(\mathrm{fT}_{4}\right)$ were moderately high and that of TSH was low. Both thyroid test and microsome test were positive. The titer in the microsome test was extremely high. TSH-binding inhibitory immunoglobulin (TBII) activity was also noticeably increased. Both CRP and ESR were slightly high. Rheumatoid factor (RF) was also increased. The titer of antinuclear antibody (ANA) was very high, and the staining pattern was of a speckled type. Although anti-ds-DNA antibody and anti-Sm antibody were negative, anti-ribosomal nuclear protein (RNP) antibody was noticeably

Table 1. Labolatory data of the patient on admission

\begin{tabular}{|c|c|c|c|c|c|}
\hline Chemistry & & & Thyroid & & \\
\hline $\mathrm{TP}$ & 8 & $\mathrm{~g} / \mathrm{dL}$ & $\mathrm{fT}_{3}$ & $9.6^{*}$ & $\mathrm{pg} / \mathrm{mL}$ \\
\hline Alb & 4.39 & $\mathrm{~g} / \mathrm{dL}$ & $\mathrm{fT}_{4}$ & $3.76^{*}$ & $\mathrm{ng} / \mathrm{dL}$ \\
\hline$\gamma$ glob & $1.97^{*}$ & $\mathrm{~g} / \mathrm{dL}$ & TSH & $0.11^{*}$ & $\mu \mathrm{U} / \mathrm{mL}$ \\
\hline TTT & $12.3^{*}$ & MU & TBII & $89^{*}$ & $\%$ \\
\hline ZTT & $19.7^{*}$ & KU & Thyroid T & $\times 10^{2 *}$ & \\
\hline TB & 0.6 & $\mathrm{mg} / \mathrm{dL}$ & Microsome $\mathrm{T}$ & $>\times 5120^{2 *}$ & \\
\hline $\mathrm{LDH}$ & 340 & IU/L & Serology & & \\
\hline AST & 30 & $\mathrm{IU} / \mathrm{L}$ & CRP & $0.6^{*}$ & $\mathrm{mg} / \mathrm{dL}$ \\
\hline ALT & $34^{*}$ & $\mathrm{IU} / \mathrm{L}$ & ESR & $27^{*}$ & $\mathrm{~mm} / \mathrm{h}$ \\
\hline$\gamma$ GTP & $123^{*}$ & IU/L & IgG & $2410^{*}$ & $\mathrm{mg} / \mathrm{dL}$ \\
\hline ALP & $412^{*}$ & $\mathrm{IU} / \mathrm{L}$ & $\operatorname{Ig} A$ & $619^{*}$ & $\mathrm{mg} / \mathrm{dL}$ \\
\hline ChE & 154 & IU/L & IgM & $331^{*}$ & $\mathrm{mg} / \mathrm{dL}$ \\
\hline Amylase & 97 & $\mathrm{IU} / \mathrm{L}$ & $\mathrm{RF}$ & $127^{*}$ & $\mathrm{IU} / \mathrm{mL}$ \\
\hline СРК & 26 & $\mathrm{U} / \mathrm{L}$ & IgG RF & $7.94^{*}$ & C.O.I \\
\hline TChol & 151 & $\mathrm{mg} / \mathrm{dL}$ & ANA-SP & $\times 5120^{*}$ & \\
\hline TGly & 134 & $\mathrm{mg} / \mathrm{dL}$ & Ant RNP Ab & $210^{*}$ & Index \\
\hline HDL Chol & $26.3^{*}$ & $\mathrm{mg} / \mathrm{dL}$ & LE factor & $+^{*}$ & \\
\hline FPG & $113^{*}$ & $\mathrm{mg} / \mathrm{dL}$ & LE cell & $+^{*}$ & \\
\hline BUN & 14 & $\mathrm{mg} / \mathrm{dL}$ & Ant LKM1 Ab & $<1$ & Index \\
\hline Creat & 0.4 & $\mathrm{mg} / \mathrm{dL}$ & Ant SM Ab & - & \\
\hline UA & 2.5 & $\mathrm{mg} / \mathrm{dL}$ & Ant $M 2 \mathrm{Ab}$ & $<5.0$ & $\mathrm{U} / \mathrm{mL}$ \\
\hline
\end{tabular}

AST, aspartate aminotransferase; ALT, alanine aminotransferase; TChol, total cholesterol; TGly, triglyceride; HDL Chol, HDL cholesterol; FPG, fasting plasma glucose; $\mathrm{fT}_{3}$, free triiodothyronine; $\mathrm{fT}_{4}$, free thyroxine; TBII, TSH-binding inhibitory immunoglobulin; RF, rheumatic factor; ANA-SP, antinuclear antibody (speckled type); Ant RNP Ab, anti-ribosomal nuclear protein antibody; LE factor, lupus erythematosus factor; Ant LKM1 Ab, anti-liver kidney microsome 1 antibody; Ant SM Ab, anti-smooth muscle antibody; Ant M2 Ab, antimitochondria 2 antibody. Abnormal values are indicated by *. 


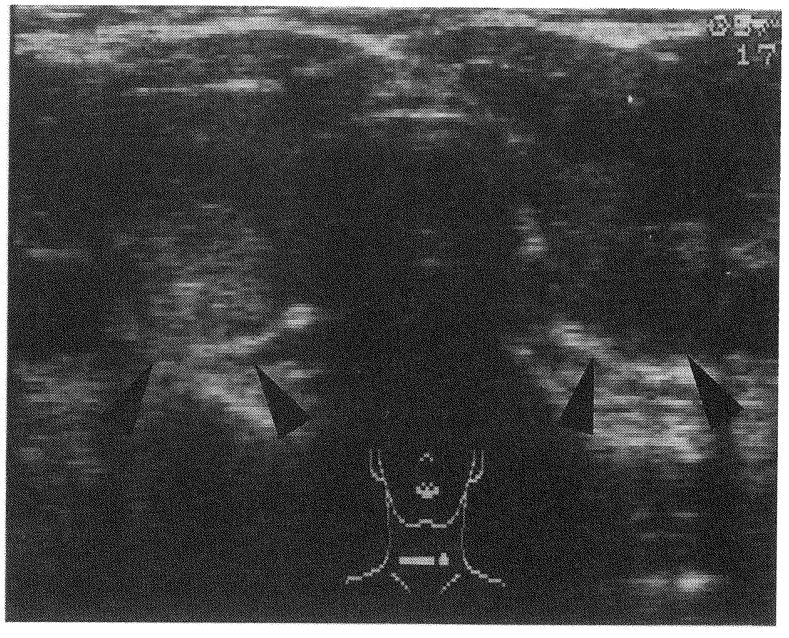

Fig. 1. Ultrasonography of the thyroid gland of this patient. Arrows in the picture indicate solid masses with cystic components in the bilateral lobes of the thyroid gland.

increased. Both LE factor and LE cell phenomenon were positive, but anti- $\mathrm{M}_{2}$ antibody was negative. $\mathrm{HBsAg}$ and $\mathrm{HBcAb}$ with dilution 200 times were negative, but $\mathrm{HBs} A b$ and $\mathrm{HBCAb}$ were positive, indicating transient hepatitis $B$ virus infection in the past. HCV antibody was negative. The serological types of human leukocyte antigen (HLA) in this case were analyzed. There were $\mathrm{A} 11$ and $\mathrm{A} 2$ in A locus, B54(22) and B60(40) in B locus, Cw1 and Cw3 in C locus, and DR4 and DR9 in DR locus.

Her ECG was normal. From the spirogram study, the vital capacity was $2.98 \mathrm{~L}(117.3 \%)$ and the $\mathrm{FEV}_{1.0 \%}$ was $82.8 \%$ (104.0\%). There was no evidence indicating the presence of pulmonary fibrosis or pulmonary hypertension.

Ultrasonography of the thyroid gland showed diffuse enlargement of the gland with several cystic and solid masses (Fig. 1). The sizes of the masses varied from 5 to $16 \mathrm{~mm}$. Scintigram of the thyroid with ${ }^{123}$ I showed generalized increased uptake to the thyroid. The rate of uptake of ${ }^{123}$ I to the thyroid was increased to $55.1 \%$ (the standard range for normal subjects in our hospital is $15-35 \%$ ). Scintigram of the thyroid with ${ }^{201} \mathrm{Tl}$ showed no abnormal uptake. Abdominal ultrasonography showed a sharp margin, smooth surface, and regular echogenecity of the liver. Liver scintigram with ${ }^{99} \mathrm{~m}$ Tc-phytate showed a liver dysfunction pattern with enlargement of the left lobe and mild

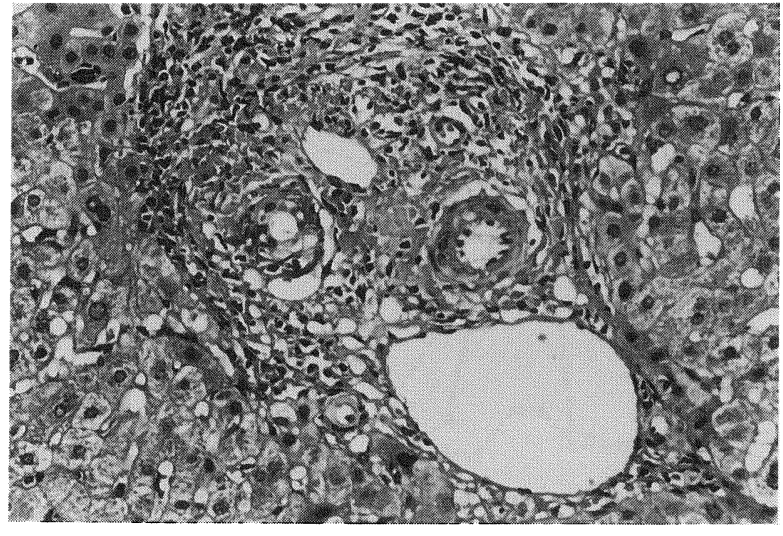

Fig. 2. Micrography of the portal area of the liver of this patient (hematoxylin-eosine staining).

uptake to the spleen. The X-ray study of the upper gastro-intestinal tract revealed no evidense of esophageal achalasia or varices.

The aspiration cytology of the thyroid mass revealed no evidence of malignancy. Histological examination of the liver by needle biopsy showed moderate disarrangement of the lobular structure with focal destruction of the limiting plate and moderate infiltration of inflammatory cells in the portal area with moderate fibrosis (Fig. 2). These histological findings were compatible with those of autoimmune hepatitis (AIH).

Fig. 3 shows the clinical course of the case. Before administration of methimazole, there was a transient increase in ALT and ESR which changed in parallel. The maximum level of ALT was 181 IU/L. After daily administration of $20 \mathrm{mg}$ of methimazole, the $\mathrm{fT}_{4}$ level rapidly went down to the normal range and the dose of methimazole was decreased to $5 \mathrm{mg}$, but during treatment with 5 $\mathrm{mg}$ of methimazole, this patient became hyperthyroid again. Therefore, $10 \mathrm{mg}$ of methimazole has been administered as a maintenance dose and $25 \mu \mathrm{g}$ of l-thyroxine has been added to maintain euthyroidism. Amelioration of hyperthyroidism and liver dysfunction seemed to occur simultaneously. Nevertheless, considering the spontaneous decrease in ALT before the administration of methimazole, it was unlikely that the decrease in ALT was solely due to the normalization of the $\mathrm{fT}_{4}$ level. 


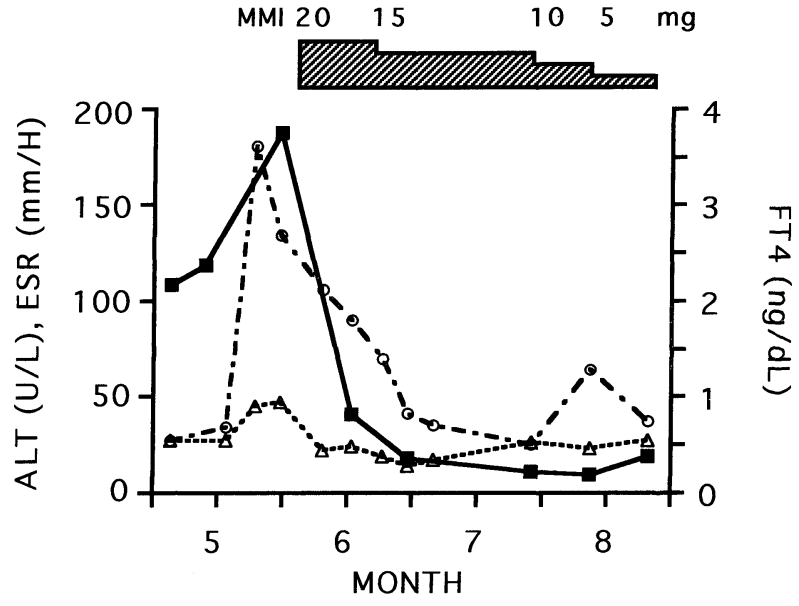

Fig. 3. Clinical course of this case. Open circle $(\bigcirc)$, open triangle $(\triangle)$, and closed square $(\square)$ indicate the levels of ALT, ESR, and $\mathrm{fT}_{4}$, respectively. ALT, alanine aminotransferase; ESR, erythrocyte sedimentation rate; $\mathrm{fT}_{4}$, free thyroxine.

\section{Discussion}

This patient was considered to have three different autoimmune diseases at the same time: Graves' disease, AIH and MCTD. A diagnosis of Graves' disease was made on the basis of such evidence as increased $\mathrm{fT}_{3}$ and $\mathrm{fT}_{4}$, depressed TSH, high TBII activity, and diffusely high uptake of ${ }^{123} \mathrm{I}$ to the thyroid gland. Graves' disease in this case was accompanied by adenomatous goiter, but multinodular toxic goiter could not be considered in this case because of high TBII activity and the absence of hot nodules in the thyroid scintigram with ${ }^{123}$ I. Graves' disease associated with adenomatous goiter is rare in Japan. Mori et al. [2] reported that 7 of 314 patients with adenomatous goiter, which was pathologically diagnosed after resection, had hyperthyroidism. Considering the very high titer of microsome test in this case, Hashitoxicosis might be the cause of hyperthyroidism. To confirm the diagnosis, a histological examination of the thyroid gland should be done.

This patient exhibited hypergammaglobulinemia, positive ANA, and LE cell phenomenon. The patient did not have anti-M2 antibody, which indicates the presence of primary biliary cirrhosis $(\mathrm{PBC})$, or any evidence of chronic viral hepatitis.
Histological findings in the liver biopsy were compatible to those of $\mathrm{AIH}$. The diagnosis of $\mathrm{AIH}$ in this case was confirmed by the diagnostic criteria $[3,4]$. As anti-LKM1 antibody was negative, this patient was diagnosed as having type $1 \mathrm{AIH}$ [4].

This patient was diagnosed as having MCTD on the basis of the findings of Raynaud's phenomenon, systemic lymphadenopathy, sausage-like swelling of the fingers, and positive anti-RNP antibody. The diagnosis of MCTD was confirmed by the diagnostic criteria [5]. This patient did not have anti-ds-DNA antibody, anti-Sm antibody or antiScl-70 antibody. Concerning organic lesions which occur in MCTD, no esophageal achalasia, lung fibrosis or pulmonary hypertension was found in this patient.

Neither a case report of Graves' disease with AIH nor a case report of Graves' disease with MCTD could be found. Furthermore, no case report of Graves' disease associated with both $\mathrm{AIH}$ and MCTD could be found. This patient may be the first one with these three autoimmune diseases concomitantly. The question then is why the patient has these three different autoimmune diseases simultaneously. Although the precise pathogenesis of these diseases has not yet been elucidated, it is difficult to find a common immunological disorder underlying the development of these three diseases, but one possible explanation would be obtained by HLA analysis of the case. Susceptibility to autoimmune diseases is considered to be genetically determined and also related to HLA. Many studies on the relationships between HLA and Graves' disease, AIH and MCTD have been reported. This patient has negative DPw2 with A11 which has been reported to relate to Graves' disease in Japanese [6], and also has DR4 which has been reported to relate to AIH in Japanese [7] and MCTD [8]. DR4 is therefore considered to relate both $\mathrm{AIH}$ and MCTD. This patient consequently has certain serological types of HLA which relate to Graves' disease, AIH and MCTD. It may be important to accumulate the results of HLA analysis of such cases as this one. Although further studies are needed to clarify common genetic factors underlying these autoimmune diseases, this case would be important in suggesting that HLA may determine susceptibility to different autoimmune diseases. 


\section{Acknowledgments}

We are gratefull to Ms. Terumi Hara for her secretarial work.

\section{References}

1. Mori T, Akamizu T, Kosugi S, Sugawa H, Inoue D, Okuda J, Ueda Y (1994) Recent progress in TSH receptor studies with a new concept of "autoimmune TSH receptor disease". Endocr J 41: 1-11.

2. Mori H, Hamada N, Mimura T, Ito K, Momotani $\mathrm{N}$, Nishikawa $\mathrm{Y}$ (1980) The incidence of hyperthyroidism in patients with adenomatous goiter. Folia Endocrinol Japon 56: 1107-1115 (In Japanese).

3. Johnson PJ, McFarlane IG (1993) Meeting report: International autoimmune hepatitis group. Hepatology 18: 998-1005.

4. Krawitt EL (1996) Autoimmune hepatitis. New Engl J Med 334: 897-903.

5. Sharp GC, Irvin WS, Tan EM, Gould RG, Holman HR (1972) Mixed connective tissue disease: An apparently distinct rheumatic disease syndrome associated with a specific antibody to an extractable nuclear antigen (ENA). Amer J Med 52: 148-159.

6. Inoue D, Sato K, Enomoto T, Sugawa H, Maeda M, Inoko $\mathrm{H}$, Tsuji $\mathrm{K}$, Mori $\mathrm{T}$, Imura $\mathrm{H}$ (1992) Correlation of HLA types and clinical findings in Japanese patients with hyperthyroid Graves' disease: Evidence indicating the existence of four subpopulations. Clin Endocrinol 36: 75-82.

7. Seki T, Kiyosawa K, Inoko H, Ota M (1990) Association of autoimmune hepatitis with HLABw54 and DR4 in Japanese patients. Hepatology 12: 1300-1304.

8. Black CM, Maddison PJ, Welsh KI, Bernstein R, Woodrow JC, Pereira RS (1988) HLA and immunoglobulin allotypes in mixed connective tissue disease. Arthritis and Rheumatism 31: 131134. 